\title{
Entering university studies: identifying enabling factors for a successful transition from school to university
}

\author{
Venicia McGhie
}

\begin{abstract}
The South African higher education sector is faced with high attrition and low retention rates. Studies conducted by the Council on Higher Education in South Africa have found that $50 \%$ of black students who access university study drop out, and the majority of dropouts occurred in the first year of study. While these studies revealed what the challenges were and why they occurred, not much has been done to overcome or prevent the challenges. Therefore, knowledge on how first-year students could be assisted and guided to adjust successful to the university environment is paramount. The goal of this article is to determine which factors enable new students' successful adjustment to the university environment. Identifying these factors was deemed important because they could be used to assist and guide new student cohorts. Thirty-two first-year students were the research participants, and data were collected from all of them through a questionnaire, two written reflective pieces, the students' results and individual interviews. Content analysis, using a three-stage open coding process, was used to categorize the findings into themes and sub-themes. The findings revealed that 20 of the 32 students had difficulty overcoming their transition challenges and failed some or all their subjects at the end of their first year of study. The remaining 12 students overcame their challenges and achieved study success. They identified three overall factors that enabled them to adjust and integrate successfully to the university environment.
\end{abstract}

\section{Introduction}

This article responds to the challenge of addressing first-year students' transition from high school to university education because researchers globally are in agreement that the first year of study is of the utmost importance for student retention and success in the subsequent years (Baijnath 1997; Bean 2005; Beyer, Gillmore, \& Fisher 2007; Krause et al. 2005; Kuh et al. 2005). Van Schalkwyk et al. (2009) put it this way: "It is little wonder then, that with the increase in student diversity internationally, educationists who seek to enhance student success should pay attention to the moment of greatest transition, the first year of study" (p. 3). Thus, this article examines new first-year students' adjustment and transition from high school to the university environment at a historically black university in South Africa during the 2009 and 2010 academic years. 
The higher education context in South Africa comprises further education and training colleges and universities. This article focuses on successful student learning at university. Grade 12 is the highest standard that students must pass at high school. They need to pass grade 12 with university endorsement in order to be admitted to university. They do not write an entrance examination, but the different faculties and disciplines have their own admission criteria with regard to prerequisite schooling subjects and percentages attained (for example, some faculties require 60\% and above in Mathematics). Historically, the universities were divided into white universities for white students only and black universities for African, Indian and coloured students. After the end of apartheid in 1994, universities became accessible to all and students could then attend any university of their choice. However, the historically white universities are still privileged because they have more capital and resources than the historically black universities. The student bodies also still reflect this divide because white students are in the majority at historically white universities and black students are in the majority at historically black universities.

Furthermore, as a consequence of apartheid, universities are characterized by a low intake of black students. Only 20\% of black grade 12 students who passed with university endorsement continue to higher education studies in South Africa (Department of Higher Education and Training 2012; Sheppard 2009). Research conducted on this issue further highlights the fact that, of the black students who access higher education, 20\% complete their respective degrees in the prescribed time, 30\% take a further 2 to 3 years to finish, and 50\% drop out before obtaining their qualifications (Council on Higher Education 2010, 2013; Scott 2009). Higher education in South Africa remains for black students, as Fisher and Scott (2011) note, "a low-participation high-attrition system" (p. 1). Their white counterparts have a $57 \%$ participation rate, a $43 \%$ completion rate and a $31 \%$ dropout rate (Council on Higher Education 2013).

The aim of the article is therefore to compare successful black students with those who are less successful with regard to their expectations, experienced challenges and applied strategies. This is in order to identify enabling factors that could assist future black student cohorts with adjusting to first-year study, thereby strengthening their chances of learning successfully. Green and Kreuter (1968) define enabling factors "as factors that make it possible (or easier) for individuals or populations to change their behavior or their environment", and this is the definition used in this article.

The main question that this article attempts to answer is: How could black first-year students be assisted to adjust successfully to the university environment? Three subquestions guide the analysis and discussion, namely the following:

1. What were new black students' expectations when they arrived at university?

2. What were the transition challenges, and how did they impact on the students' academic and social integration?

3. What did the successful students do to overcome their challenges and integrate into the university environment? 


\section{Theoretical orientation}

There is a wealth of research conducted on student learning and the transition of first-year students from school to college/university education (Bowles et al. 2014; Green et al. 2009; Kuh et al. 2011; Pascarella and Terenzini 2005; Strydom \& Mentz 2010). Kuh et al. (2011), for example, state that "...many students who are college-ready encounter campus cultures that feel foreign and unfriendly, making college challenging for them to navigate successfully" (p. 13). In this regard, Mann (2005) explains how students' feelings of alienation can impact negatively on their transition from school to the university environment. Other studies conducted on students' transition identified a heavy workload, students' inability to manage their time effectively, a lack of personal motivation, financial difficulties, insufficient foundational knowledge and their status as first-generation students as some of the most important challenges that first-year students experience when arriving at university (Beyer, Gillmore \& Fisher 2007; Cloete 2012; Community College Review 2015; Einfalt \& Turley 2013; Letseka \& Maile 2008).

It is against this background that this article uses Tinto's $(1975,2000)$ student integration model and Bandura's $(1986,2001)$ social cognitive theory as a theoretical orientation. Tinto's (1975) student integration model suggests that a match between the academic ability and motivation of the student, and the social and academic qualities of the institution, will strengthen the academic and social integration of the students into the university system. Tinto's (1975) student integration model consists of six characteristics:

1. Pre-entry attributes (how the student develops before entry into post-secondary education with regard to family background, skills and abilities and prior schooling)

2. The student's intentions, goals and commitment

3. How the student experiences the institution with regard to the academic system (academic performance, interaction with staff and faculty) and the social system (extra-curricular activities and peer group interaction)

4. How integration is taking place (both academic and social integration)

5. The student's intentions, goals, institutional commitment and external commitments

6. The outcome (decision by the student to remain or to depart)

Tinto is of the opinion that the match between student characteristics and the institution shapes student goals and commitments which, in turn, influences persistence (Tinto 1975). In addition, in his discussion on building supportive peer groups, Tinto explains that meeting people and making friends during the first year of university study are an important aspect of student life that could assist with the social integration of students and the transition from school to university (Tinto 2000).

Bandura (1986) describes his social cognitive theory as human functioning "in terms of a model of triadic reciprocality in which behavior, cognitive and other personal factors, and environmental events all operate as interacting determinants of each other" (p. 18). He explains that "learning is largely an information-processing activity in which information about the 
structure of behavior and about environmental events is transformed into symbolic representations that serve as guides for action" (Bandura 1986, p. 51). According to him, "most external influences affect behavior through intermediary cognitive processes in that cognitive factors to a certain extent determine which environmental occurrences will be observed, what meaning will be derived from them, whether they leave any lasting effects, what valence and value they will have, and how the information they communicate will be organized for future use" (Bandura 1986, p. 454). He further argues that self-regulatory and self-reflective capabilities have to do with human beings' perceived self-efficacy, and he defines perceived self-efficacy "as people's judgments of their capabilities to organize and execute courses of action required to attain designated types of performance" (Bandura 1986, p. 391). He is of the opinion that "perceived self-efficacy is an important determinant of performance that operates to a certain extent independently of underlying skills" (Bandura 1986, p. 391).

Bandura (2001) further claims that his social cognitive theory "subscribes to a model of emergent interactive agency", which in turn differentiates among three different modes of agency: personal, proxy and collective agencies (p. 4). Personal agency refers to the cognitive, motivational, affective and choice processes of individuals; proxy agency refers to the social conditions and institutional practices that affect people's everyday lives. Proxy agency means that people rely on other people, who are in positions of power, to act on their behalf and to secure the outcome that they want. Collective agency refers to people's shared belief in their collective power to produce desired results. It serves the same role as that of personal efficacy beliefs and functions through similar processes (Bandura 2001, pp. 13-14).

Tinto's student integration model focuses on two of the main role players in the learning process-the characteristics of the student and the qualities of the institution. He argues that these two role players need to be compatible for successful student integration to take place. Bandura's social cognitive theory is used in this study to illustrate that learning is developmental and a socially constructed process in which students need to know what their capabilities are, and how to use their three modes of agency to help them navigate the learning environment successfully. Therefore, Tinto and Bandura's theories are used to augment each other in this article and form the theoretical foundation upon which the analysis and discussion of the findings are based.

\section{Methods}

The data discussed in this article were derived from a study conducted during the 2009 and 2010 academic years in a business faculty at a historically black university in South Africa. It was a qualitative study searching for an understanding of a problem in a specific context (Creswell 2007; Yin 2009). The research participants were two groups of new first-year students, with 20 students in the one group and 12 in the other. A purposive sampling method (Patton 2002) was used to select the students because it was important to have mixed-ability groups-that is, students who found the adjustment to university challenging and, as a result, failed one or more of their subjects and students who adjusted successfully and passed all their subjects. The 20 students in the first group were students who could not overcome their 
transition challenges and failed some or all their subjects at the end of their first year of study. They were referred to as group 1, the less successful group. The 12 students in the second group were students who overcame their adjustment challenges and passed all their subjects. They were referred to as group 2, the successful group. It should be noted that this group had 20 students at the start of the study as well, but eight of them failed one or two of their subjects at the end of the first semester and had to withdraw as participants.

The selection of the two groups of students took place in the first week of term 2, 2009, when the students were in their first semester of their first year of study in the course taught by the researcher. The first semester, made up of terms 1 ( 7 weeks) and 2 ( 7 weeks), started at the end of January and ran to the end of May. The second semester, made up of terms 3 (7 weeks) and 4 (7 weeks), ran from mid-July to the end of October. The researcher requested the students to write a reflection on their experiences as new first-year students and to state whether or not they were passing their assignments and tasks in term 1. All the students who indicated that they had adjustment challenges and were failing their assignments and tasks were identified by the researcher and invited to participate in the study via an email. There were 102 students in total. The first 20 students who responded and agreed to be part of the study were selected and formed group 1 . The students who formed group 2 were selected in the same way, but these were the students (74 in total) who were passing their assignments and tasks despite experiencing adjustment challenges.

Group 1 consisted of 13 females and seven males with a mean age of 19.4. Ten students were African, nine coloured and one Indian. Six of them were registered for the Bachelor of Administration Degree, and 14 were registered for the Bachelor of Commerce Degree. Group 2 consisted of eight females and four males with a mean age of 19.7. Four students were African, six coloured and two Indian. Four students were registered for the Bachelor of Administration Degree and eight for the Bachelor of Commerce Degree. Both groups of students had passed grade 12 with university endorsement, and all of them came from low socio-economic backgrounds and public schooling. Thirty of the students were first-generation students.

The reflective piece that the students wrote during the first week in term 2 was used as the first data set. The other data sets consisted of the students' biographical information, a second written reflection, a questionnaire, individual interviews and their end-of-year results. The written reflections were not longer than one page, and guiding questions were provided to the students as stated in Table 1. The questionnaire consisted of two parts. Part 1 had six closed-ended questions that focused on the students' biographical information, and part 2 had five open-ended questions. An interview sheet was prepared for the students, and they wrote their responses on the sheet during the interviews. The researcher administered the questionnaire and conducted the interviews with all 32 students. The marks' administrator was requested to extract the students' biographical information from the university's database, as well as the students' end-of-year results. Table 1 reflects the data sets, the timeframe and the questions asked.

The biographical information and the students' end-of-year results were regarded as quantitative data and were grouped and sorted in two separate tables. Content analysis, using 
a three-stage open coding process, was used to analyze and sort the qualitative data-the two reflective written pieces, part 2 of the questionnaire and the responses in the individual interviews (Henning 2004). The first stage of the open coding process involved a first general reading and noting of all the responses per data set. These responses were typed in two separate Word documents (one for group 1 and one for group 2). In stage 2, line-by-line reading was done in order to identify and group similar responses together across data sets and to list separately the responses that were different. Hence, all the responses that were similar and different were copied from the first Word documents and pasted onto two new Word documents (one for each group).

The third and final stage involved grouping together related themes and sub-themes in another two Word documents. In the end, each group had three separate Word documents. The Word documents were checked against the original data by an independent researcher in order to ensure that the students' responses were correctly typed, copied and pasted in the three Word documents. Triangulation was achieved through the verification of the students' biographical information (extracted from the university's database) with the students' own answers in part 1 of the questionnaire. The students' 2009 end-of-year results were used to verify their answers in the reflective pieces regarding whether they were passing or failing. Lastly, triangulation was further achieved through a repeat of the main question-what were your challenges and how could you overcome them-in the reflective written pieces and in the second part of the questionnaire and through the second question asked in the individual interviews. 
Table 1 Data sets, timeframe and questions asked

\begin{tabular}{|c|c|c|}
\hline Data sets & Timeframe & Questions asked/instructions given \\
\hline $\begin{array}{l}\text { First written reflective } \\
\text { piece }\end{array}$ & $\begin{array}{l}\text { 1st week in term 2, April } \\
2009\end{array}$ & $\begin{array}{l}\text { To reflect on their experiences in term } 1 \text { : } \\
\text { 1. What their expectations were } \\
\text { 2. What was positive about their studies } \\
\text { 3. How they were progressing } \\
\text { 4. What the challenges were and the impact of these }\end{array}$ \\
\hline $\begin{array}{l}\text { Biographical } \\
\text { information }\end{array}$ & $\begin{array}{l}\text { 5th week in term 2, } \\
\text { May } 2009\end{array}$ & $\begin{array}{l}\text { Age, gender, race, language, schooling background and } \\
\text { parents' income (extracted from university's } \\
\text { database) }\end{array}$ \\
\hline $\begin{array}{l}\text { Second written reflective } \\
\text { piece }\end{array}$ & $\begin{array}{l}\text { 1st week in term 3, } \\
\text { July } 2009\end{array}$ & $\begin{array}{l}\text { To reflect on their first semester (terms } 1 \text { and } 2 \text { ): } \\
\text { 1. Which subjects passed and why } \\
\text { 2. Which subjects failed and why (challenges) } \\
\text { 3. What could they change/do differently in the second } \\
\text { semester in order to overcome the challenges }\end{array}$ \\
\hline Questionnaire & $\begin{array}{l}\text { 2nd week in term 4, } \\
\text { October } 2009\end{array}$ & $\begin{array}{l}\text { Part 1: biographical info: age, gender, race, language, } \\
\text { schooling background and parents' income } \\
\text { Part 2: qualitative questions } \\
\text { 1. Why do you study in a business faculty } \\
\text { 2. Do you have accommodation } \\
\text { 3. What is your financial situation } \\
\text { 4. Do you receive support from your family and friends } \\
\text { 5. Do you still have challenges and/or new ones, and } \\
\text { how could you overcome them }\end{array}$ \\
\hline 2009 end-of-year results & $\begin{array}{l}\text { 3rd week in term 1, } \\
\text { February } 2010\end{array}$ & $\begin{array}{l}\text { The } 2009 \text { end-of-year results were extracted from the } \\
\text { university database in February the next year (thus, } \\
\text { at the beginning of 2010) }\end{array}$ \\
\hline Individual interviews & $\begin{array}{l}\text { 5th week in term 1, } \\
\text { March } 2010\end{array}$ & $\begin{array}{l}\text { The interviews were conducted during term } 1,2010 \text {, } \\
\text { when the students were in their second year of study. } \\
\text { Two questions were asked: } \\
\text { 1. What did you learn during your first year of study? } \\
\text { 2. What advice would you give to new students in order } \\
\text { to overcome their transition challenges? }\end{array}$ \\
\hline
\end{tabular}

\section{Results}

The section is structured according to the three sub-questions previously stated. The students' expectations are summarized in Table 2 and discussed first. Thereafter, only the transition challenges are summarized in Table 3 and discussed. The students did identify other personal challenges (needing financial assistance and on-campus accommodation, not receiving moral support and encouragement from their families, home environments not being conducive for learning, and the demands of working and studying simultaneously), but because the focus of this article is on first-year students' transition and integration into the university environment, the personal difficulties are not discussed. 
Table 2 Students' responses to the question on what their expectations were

\begin{tabular}{ll}
\hline Group 1 (20 students): less successful group & Group 2 (12 students): successful group \\
\hline $\begin{array}{l}\text { Sub-theme 1: freedom and making friends } \\
\text { Looked forward to making new friends, learning new } \\
\text { cultures, and having freedom }\end{array}$ & $\begin{array}{c}\text { Sub-theme 1: heavy workload and hard work } \\
\text { was needed } \\
\text { University would be much more difficult and } \\
\text { complicated than school; the workload would be } \\
\text { heavy and hard work would be needed (10 students) }\end{array}$ \\
$\begin{array}{l}\text { Sub-theme 2: uncertainty } \\
\text { Excited but anxious ( } 3 \text { students) }\end{array}$ & $\begin{array}{c}\text { Sub-theme 2: good lecturers and organized staff } \\
\text { Expected good lecturers and organ ized staff }\end{array}$ \\
$\begin{array}{l}\text { Scared and finding it stressful; do not know } \\
\text { what to expect ( } 8 \text { students) }\end{array}$ & $\begin{array}{l}\text { (2 students) } \\
\text { Sub-theme 3: hard work was needed } \\
\text { University will be different from school and hard } \\
\text { work would be needed (5 students) }\end{array}$ \\
\hline
\end{tabular}

What were the students' expectations when they arrived at university?

This question was asked to determine if the students had some idea of what university study entails and whether they were prepared for university studies. It was asked in written reflection 1, during the first week in term 2, April 2009. Three sub-themes emerged from group 1: freedom, uncertainty, and the need for hard work. Only two sub-themes were identified in group 2: hard work and good lecturers and organized staff. The responses are summarized in Table 2.

The responses from four students in group 1 indicate that their expectations of attending university were centred on making new friends, learning new cultures and having freedom. Responses were as follows:

Student 4: I looked forward to meet new friends and learn new cultures. Student 1: University means freedom to do what I want.

Student 3: University means no more teachers watching over you.

Table 3 Transition challenges reported by the students

Group 1 (20 students): less successful group

Struggling to adjust to university environment (14 students)

Perceiving the workload as heavy (12 students)

Struggling with time management (7 students)

Finding the subject content challenging (14 students)

Finding the English language challenging (7 students)

Giving in to peer pressure (4 students)
Group 2 (12 students): successful group

Struggling to adjust to university environment (10 students)

Perceiving the workload as heavy ( 7 students)

Struggling with time management (7 students)

Finding the subject content challenging

(6 students) 
Thus, these students viewed university as a place where they had freedom to do what they wanted, as opposed to school where they were subjected to strict rules and being under observation by their teachers, principals and parents.

Furthermore, one could infer that the three students who reported that they felt excited but anxious, and the eight who were scared and stressed, did not know what to expect at university. They therefore experienced feelings of anxiety, fear and stress. Responses were as follows:

Student 8: I was very excited to come to university because it is a new place, but a little afraid too.

Student 12: I was excited to be at university but also anxious because I did not know what to expect.

Student 14: I was scared and stressful because everything was new.

Their responses show that they were not adequately prepared for university studies on a personal and emotional level and that they therefore had mixed feelings-positive (feeling excited) and negative (anxiety, fear and stress).

Lastly, responses from the students who expected that university would be different from school and that hard work was needed were as follows:

Student 7: At first I didn't know what to expect, I just knew varsity is at a higher level than high school and that I had to work harder.

Student 9: University will be different from school, so I have to work harder.

Their responses indicate that they had some idea of what university study required and that they needed to work hard in order to be successful. In summary, the responses in group 1 reflect that 15 students did not know what to expect and what university studies would entail, while only five of them knew that hard work was required.

On the other hand, the responses from group 2 reflect that ten out of the 12 students were knowledgeable about university studies. They wrote the following:

Student 1: I know that it would be much difficult and complicated than school and the workload would be heavy and I needed to work hard.

Student 2: University is different from school and I have to work hard and spent lots of my time on concentrating on my work.

These students knew that university study would be more demanding than school, with more work assigned, and that as a result, they had to apply themselves to be successful.

The other two students' expectations about the staff imply that they were looking for quality education. Their responses were as follows: 
Student 6: I expected good lecturers and organized staff because it is a university. Student 10: I hope that the staff will be good and organized.

One could infer from the word "organized" that they expected everything to be planned, structured and orderly conducted, which signified a certain standard of quality. This could mean that they were hard-working students at school and would continue in the same manner at university level. As such, they were expecting to receive quality education in return for their hard work. One could therefore conclude that the students in group 2 knew from the start of their academic careers that university was different to school and that they had to work hard.

What were the transition challenges and how did they impact on students' academic and social integration?

This question was asked in both reflective pieces-first in term 2, April 2009, and again in term 3, July 2009. It was also asked in the questionnaire in October 2009. Group 1 reported six transition challenges, while group 2 experienced four challenges.

The responses illustrate that both groups of students identified the same four challenges, but the students in group 2 did not report a language challenge nor that they gave in to peer pressure. What is important about the findings is the number of students from both groups who experienced the first challenge compared to the number of students experiencing the other challenges. Fourteen students in group 1 and ten in group 2 reported on the first challenge. Thus, the majority of the students found the changeover from high school to university demanding which is in line with other research conducted on this matter. Explanations given by the students in group 1 were as follows:

Student 1: I also was overwhelmed by the freedom at varsity because everything was new to me and I could do what I wanted and before I knew it the exams was coming up and I was caught up in having too much fun.

Students 3, 4 and 6: Adjusting to university life was hard, I used my freedom incorrectly and having too much fun.

These two students were the same students who reported that they looked forward to having freedom. Their responses indicate that they abused their freedom and did not take studying at university seriously because they were not prepared for university studies on a personal level (emotionally and psychologically), and so, they gave in to peer pressure. In addition, they were also among the students who reported that they found the content of certain subjects challenging. Responses were as follows:

Students 3 and 4: My challenge is not being taught certain things at school and learning it for the first-time at university.

Student 6: Maths-didn't do it at high school so had to do it at varsity so that caused a problem. 
Their responses illustrate that they were also academically not prepared for university studies. Moreover, seven of the 14 students reported that they had a language problem because they were from high schools where they were taught in their mother tongue and not in English.

Responses were as follows:

Students 8 and 14: The medium of instruction is too difficult. I cannot understand the presentation.

Student 12: It is difficult to understand the lecturers in English, at school I learned in my first language.

These students had to listen, understand and make meaning in English at an advanced level for the first time, which is a major disadvantage, as Gough (1996) notes: "If you are not proficient in the dominant language, you are handicapped and there is no getting away from it" (p. 17). Therefore, an argument could be made that the students in group 1 had to deal with four and more challenges (the personal difficulties which some also identified) simultaneously and they did not know how to overcome them. It was as if they surrendered to the challenges, and as a consequence, some of them failed two subjects, some three and four, and two students failed all their subjects at the end of their first year of study.

Similar to group 1, ten students in group 2 also reported that they found the adjustment to university challenging. Responses were as follows:

Student 1: Adjusting to university is hard and I struggle to manage my timetable and to fit everything in.

Student 2: Adjusting to university life is hard because there is no time to socialize.

These two students were among the students who indicated that they knew that university would be different and hard work was required. However, it seems as if they did not know the extent of the hard work and effort that was required and that was why the adjustment to university was a challenge for them.

Some of the other students' responses were as follows:

Students 3 and 4: Some subjects are difficult and it is a lot of work that one must learn.

Students 6, 7 and 9: The content of some of the subjects were challenging, we did not have these subjects at school.

These responses illustrate that the students in group 2 were also challenged by the content of some of the subjects for which they were registered. This indicates that they, too, were not prepared for university studies academically. However, the difference between the two groups is that the students in group 2 made a concerted effort to overcome their challenges and they managed to pass all their subjects at the end of their first year. 
What did the successful students do to overcome their challenges and integrate into the university environment?

The students in group 2 explained what they did to overcome their transition challenges. Responses were as follows:

Student 1: The only way I can make a real success out of this study period is to stay focused at all times possible.

Student 2: I must know why I am here which is to complete my studies.

Student 6: I remained a hardworking and competent student throughout the semester.

These responses show that the students realized that they had to take responsibility for their own learning, and as a consequence, they reminded themselves as to why they were at university (presumably to achieve their goals and objectives). Staying focused was the action needed to achieve their goals and objectives.

One factor that most probably assisted these students was the fact that they started with the expectation that university would be different to school and that hard work was required.

Another factor contributing to the success of the students could be that they had the support and encouragement of their family members who helped them to 'stay focused' and work harder. Students explained the following:

Student 1: My family and friends have been very supporting throughout this whole process, which encourages me even more, and every day I wake up and realise the little things in my life and how important they are towards shaping the mentality of an individual.

Student 2: My life, my family, my home and my community are my inspiration to go forward, to strive for perfection and reach for the stars even if I might never come to know how it feels like to be there. These are all the reasons that keep me going and determined to succeed with everything in me, which further reflects in my academic work.

The students in group 1 did not mention that they received support and encouragement from their families, and that could be a reason why they were not motivated enough to change their behaviour.

Additionally, all the students in group 2 reported and emphasized that they 'made the right friends'-friends who supported and encouraged them and assisted them academically. They wrote the following:

Student 8: I chose friends who had the same focus and determination-I found that when we worked together, things always seemed more positive and we enjoyed our studies and tried to make even the worst subjects fun by talking about it. 
Student 12: Surround yourself with positive peers or better yet help encourage and motivate others to join you in reaching a goal. Knowing you can help \& support each other, makes learning less stressful and fun.

All 12 students wrote, 'Make the right friends from the start of your academic studies', as part of their responses on the interview sheets. They also explained how they overcame their perceived heavy workload and time management challenges. They wrote the following:

Student 3: My social life was extremely important me, so I had to manage my time correctly and prioritise what was most important and required my time. I worked from a system whereby I created an electronic diary via an excel spreadsheet. I would update this sheet weekly or even daily. The sheet portrayed information about assignments, tests, tutorial test, etc. As well as due dates, my progress as well as the next date I need to progress on it. I used "auto filler" to filter check what I needed to focus for the specific week. This allowed me to plan my week and avoided time wasted on projects.

Student 4: With all the assignments, tutorials and tests that had to be done, effective time management was going to be of utmost importance. I would then record all test dates and due dates as soon as they were made available to me and then try and allocate time that I estimated to be efficient for each task at hand. I also tried my best to study before the time for a test and not leave things for the last minute as I found that it only creates more anxiety and stress that does not help you with what you have to do.

These detailed explanations reveal how the changed attitudes of the students transformed into dedication and commitment; the adoption of learning strategies assisted them in overcoming their perceived workload and time management challenges. These strategies helped them to adjust successfully to the demands made by academia.

Lastly, the students demonstrated not only that they adopted effective time management strategies, but also that they made a conscious effort to find solutions to their challenge about not understanding the content in some of their subjects. They indicated that they, as they put it, 'were not afraid to ask questions' or to find help when 'needed' and 'to go for consultation'. Explanations were as follows:

Student 3: And also do not be afraid to ask for help, nobody expects you to always be good at everything. I often stayed after class and asked the lecturer questions about things I did not understand and they would stay behind and explain it to me until I did, if they could, or I made use of consultation times.

Student 4: I asked questions when I did not understand and I went for consultation. It helped to clarify the work and I was able to understand it better. 
Student 9: I asked questions when something was not clear and I went for consultation and I received clarification on work covered. Consultation helped with preparation for tests and exams.

These responses demonstrate that they attended their classes. More importantly, the responses reflect that the students' perceived self-efficacy was high because they were not afraid to ask questions when they did not understand something. Furthermore, they consulted with the lecturers-both after class and during consultation times. These were important actions that helped them to overcome their challenge of not understanding the content in some subjects. As a result, they passed all their subjects at the end of their first year of study.

\section{Discussion}

The analysis was structured around three factors: the students' expectations when they arrived at university, the transition challenges that they experience and the strategies that they applied to overcome the challenges. The results showed that only five of the 20 students in group 1 had the correct expectations of what university study entails and that it was different from school and hard work was required. The other 15 students' expectations ranged from being excited but anxious, to making new friends, learning new cultures and having freedom. These expectations were not incorrect because it is normal to be excited and anxious when one embarks on a new and unknown journey, and it is equally justified to think that one will have more freedom once one has completed high school. However, what the students did not realize was the magnitude of the difference between school and university and that freedom comes with responsibility.

Nonetheless, the students' historical backgrounds could be regarded as mitigating circumstances. They came from low socio-economic backgrounds and public schooling and were all first-generation students. The students' parents and families were part of the working class and poorer people in the communities; the public schools in South Africa are not well resourced (many do not have Mathematics, Physics and Biology as subjects, or libraries, and some of the teachers are under-qualified), and they did not come from an academic tradition where it was the norm to attend university. As such, these pre-entry attributes to which Tinto refers did not prepare nor enable them to overcome their challenges and adjust to the demands of academia.

The students in group 2 came from the same backgrounds, having attended public schools, and ten of the 12 were also first-generation students. However, the difference between the two groups of students was that, unlike most of the students in group 1, all the students in group 2 came with the 'correct expectation', which was that university was different from school and hard work was required. They did not think about having freedom and doing what they wanted; they knew that they had to take responsibility for their own learning and that was why they were prepared to work hard so that they could be successful in their studies. Their actions reflect the intentions, goals and commitment that Tinto advocates that students should have.

The analysis also illustrated that both groups of students experienced challenges and four of the six challenges were similar. Both groups found the adjustment to university challenging, 
perceived the workload as heavy, struggled to manage their time effectively and found the content of some subjects difficult. The difference was that the students in group 1 identified two further challenges-having to learn in English, which was not their first language, and giving in to peer pressure. The students in group 2 did not have such challenges. One could therefore argue that the students in group 1 experienced more challenges, and that was why they surrendered and were less successful at the end of their first year of study. In contrast, the students in group 2 were able to overcome their challenges and to pass all their subjects.

Which strategies did the students in group 2 use to overcome their challenges? They reminded themselves why they were at university and chose to stay focused, determined and hard working. They used their personal agency (explained by Bandura); they took responsibility for their own learning and became self-regulatory students whose perceived self-efficacy helped them to organize and execute courses of action required to attain their goals (Bandura 1986, 2001). But they also used their proxy and collective agencies to assist them. They were motivated by the support and encouragement which they received from their parents and friends at home. This was moral and emotional support and not academic support, as ten of the 12 students were also first-generation students. Hence, the support that they received motivated them to work hard and succeed so that their families could be proud of their achievements. These students demonstrated that first-generation students could also be successful as found by O’Shea (2015).

Moreover, by attending classes, asking questions and making use of consultation, the students actively strengthened their academic integration. This is what Pascarella and Terenzini (2005) explain, "The greater a student's engagement in academic work or in the academic experience of college, the greater his or her level of knowledge acquisition and general cognitive growth" (p. 608). Not only did they strengthen their academic integration, but they also strengthened their social integration by identifying and selecting the "right friends'. Therefore, their responses and actions show that they placed a high value on both their proxy and collective agencies (Bandura 1986, 2001) and, in so doing, overcame their transition challenges and integrated successfully into the university environment as Tinto $(1975,2000)$ suggests that should happen.

However, the behaviours and actions of the students in group 1 were the opposite. They focused on the freedom and fun available to them as university students, resulting in devastating consequences. Having a laid-back attitude led to the perception that university study was 'difficult and hard', and as a consequence, they could not cope with the demands made by academia. Also, not attending classes and giving in to peer pressure showed ineffective time management, and this caused their perception that the workload as 'heavy'. Thus, they too used their proxy and collective agencies but in a negative manner (Bandura 1986, 2001). Lastly, lacking adequate preparation for academic study, experiencing some of their subject content as challenging and having to learn and think in English for the first time severely compromised their academic integration into the university environment (Tinto 1975, 2000). Although this was a small sample which makes the findings context specific, the reality in South African higher education is that the majority of black students are not prepared for 
university studies and that is what the students in group 1 demonstrated. However, the students in group 2 showed that, despite coming from the same circumstances, successful learning is possible, and this is the significance of this article. And as stated in the "Method" section, group 2 also had 20 students at the start of the study, but eight students failed some of their subjects at the end of the first semester and had to withdraw from the successful group. Therefore, the fact that more students failed and fewer students passed mirrored the discussion in the introductory section-black students at universities in South Africa have a high failure and dropout rate in the first year of study and an overall dropout rate of $50 \%$ across the study period for a first degree.

\section{Conclusion and recommendations}

Two overall findings could be inferred from the analysis of the successful group of students: (i) successful learning at university begins with the students (thus, the application of personal agency and self-efficacy), and (ii) students cannot be successful on their own; they need the assistance and support of the other role players in the learning process (proxy and collective agencies). Consequently, prospective black students need to use all three modes of agency to integrate successfully into the university environment.

Three enabling factors could be identified from the successful students in group 2, namely the following:

1. They arrived at university with the correct expectations (they were knowledgeable as to what university study entails) and took responsibility for their own learning from the start of their academic careers.

2. They used the motivation and encouragement received from their families and friends as self-motivation to succeed.

3. They made smart choices-they applied all the strategies that other studies also identified: they made the right friends, attended all their classes, asked questions and spoke to the lecturers inside and outside of classes and made use of consultation.

It is therefore recommended that future black students should be informed and prepared for university study so that they too will know what to expect and take responsibility for their own learning from the start of their degree programs.

It is further recommended that parents and families should know and be made aware of the importance of providing moral support and encouragement to their children throughout their study careers.

Finally, it is recommended that all the role players (parents, families, friends, communities, schools, universities and authorities) encourage, guide and assist the students so that they are able to make smart choices, as the students in this article demonstrated that making good decisions is vital for academic success. 
The findings discussed in this article exemplified that black students can overcome their transition challenges and integrate successfully into the university environment despite their unfavourable pre-university attributes. The recommendations proposed are guidelines that the different role players could follow in order to increase black students' chances at successful learning and, in so doing, improve the pass, retention and completion rates nationally. An emerging economy such as South Africa needs educated, skilled and productive citizens who can help to develop and sustain the future for generations to come. Successful student learning can contribute to this objective. 


\section{References}

Baijnath, N. (1997). Facilitating educational change: academic development in a university setting. Unpublished D Phil dissertation, University of the Western Cape .

Bandura, A. (1986). Social foundations of thought \& action. A social cognitive theory. New Jersey: Prentice- Hall, Inc..

Bandura, A. (2001). Social cognitive theory: an agentic perspective. Annu Rev Psychol, 52, 126.

Bean, J. (2005). Nine themes of college student retention: factors predicting the success of first- year, first- semester students at Tennessee State University. Doctorate Dissertation, Tennessee State University.

Beyer, C. H., Gillmore, G. M., \& Fisher, A. T. (2007). Inside the undergraduate experience. The University of Washington's study of undergraduate learning. Bolton, MA: Anker Publishing Company, Inc..

Bowles, A., Fisher, R., McPhail, R., Rosentreich, D., \& Dobson, A. (2014). Stay the distance: students' perceptions of enablers of transition to higher education. High Educ Res Dev, $33(2), 212-225$.

Cloete, N. (2012). Synthesis. In: Responding to the educational needs of post school youth: determining the scope of the problem and developing a capacity-building model. Wynberg: Centre for Higher Education Transformation.

Community College Review. (2015). At-risk students find success at community colleges community. Community college review.com. Accessed 30 May 2015.

Council on Higher Education (2010). Access and throughput in South African higher education: three case studies. (Higher education monitor no 9). Pretoria: Council on Higher Education.

Council on Higher Education (2013). A proposal for undergraduate curriculum reform in South Africa: the case for a flexible curriculum structure. In Report of the Task Team on undergraduate curriculum structure. Pretoria: Council on Higher Education.

Creswell, J.W. (2007). Qualitative inquiry and research design. Choosing among five approaches. (2nd edition). California: Sage Publication, Inc.

Department of Higher Education and Training (2012). Green article for post education and training. Pretoria: Department of Higher Education and Training.

Einfalt, J., \& Turley, J. (2013). Partnerships for success: a collaborative support model to enhance the first year student experience. The international journal of the First Year in Higher Education, 4(1), 73-84.

Fisher, G. \& Scott, I. (2011). Closing the skills and technology gap in South Africa: background Article 3. The role of higher education in closing the skills gap in South Africa. The World Bank

Gough, D. (1996). Myths of multilingualism: demography and democracy. AD Issues, 4(1), 4042.

Green, P., Cashmore, A., Scott, J., \& Narayanan, G. (2009). Making sense of first-year student life: transitions as ethnographic process. In B. Leibowitz, A. Van der Merwe, \& S. Van Schalkwyk (Eds.), Focus on first-year success. Perspectives emerging from South Africa and beyond (pp. 47-56). Stellenbosch: SUN MeDIA. 
Green, L. W. \& Kreuter, M.W., (1968). PRECEDE-PROCEED model of community health promotion planning and evaluation. http://www.encyclopedia.com/doc/1G23404000298.html. Accessed 12 February 2016.

Henning, E. (2004). Finding your way in qualitative research. Pretoria: Van Schaik Publishers.

Krause, K., Hartley, R., James, R., \& McInnis, C. (2005). The first year experience in Australian universities: findings from a decade of national studies. Canberra: Australian Department of Education, Science and Training.

Kuh, G. D., Kinzie, J., Schuh, J. H., \& Whitt, E. J. (2011). Fostering student success in hard times. Change: The Magazine of Higher Learning, 43(4), 13-19.

Kuh, G. D., Kinzie, J., Schuh, J. H., Whitt, E. J., \& Associates (2005). Student success in college. Creating conditions that matter. San Francisco: Jossey-Bass Publishers.

Letseka, M., \& Maile, S. (2008). High university drop-out rates: a threat to South Africa's future. HSRC policy brief. Pretoria: HSRC Press.

Mann, S. J. (2005). Alienation in the learning environment: a failure of community? Stud High Educ, 3o(1), 43-55.

O'Shea, S. (2015). Avoiding the manufacture of 'sameness': first-in-family students, cultural capital and the higher education environment. Higher Education Journal. 15-9938-y.15-9938-y.

Pascarella, E. T., \& Terenzini, P. T. (2005). How college affects students. Volume 2. A third decade of research. San Francisco: Jossey-Bass.

Patton, M. Q. (2002). Qualitative research \& evaluation methods (3rd ed.). California: SAGE Publications, Inc.. Scott, I. (2009). First-year experience as terrain of failure or platform for development? Critical, choices for higher education. In B. Leibowitz, A. Van der Merwe, \& S. Van Schalkwyk (Eds.), Focus on first-year success. Perspectives emerging from South Africa and beyond (pp. 17-35). SUN MeDIA: Stellenbosch.

Sheppard, C. (2009). The state of youth in South Africa: trends in education attainment. Centre for poverty employment and growth. Pretoria: Human Science Research Council.

Strydom, J. F., \& Mentz, M. (2010). South African survey of student engagement . Pretoria: Council on Higher Education.Focusing the student experience on success through student engagement. Council on Higher Education

Van Schalkwyk, S., Leibowitz, B., \& Van der Merwe, A. (2009). Introduction. Perspectives on the first-year experience. In B. Leibowitz, A. Van der Merwe, \& S. Van Schalkwyk (Eds.), Focus on first-year success. Perspectives emerging from South Africa and beyond (pp. 3-13). Stellenbosch: SUN MeDIA.

Tinto, V. (1975). Dropout from higher education: a theoretical synthesis of recent research. Rev Educ Res, 65(1), 89-125.

Tinto, V. (2000). Linking learning and leaving. Exploring the role of the college classroom in student departure. In J. M. Braxton (Ed.), Reworking the student departure puzzle (pp. 81-94). Nashville: Vanderbilt University Press.

Yin, R. K. (2009). Case study research. Designs and methods Publications. 
https://repository.uwc.ac.za/ 